\title{
Validation and Use of Quality of life Impact of Refractive Correction Questionnaire in Spectacle Wearers in Malawi: A clinic-based study
}

\author{
Dinesh Kaphle ${ }^{1,2,3^{*}}$, Himal Kandel ${ }^{4}$, Jyoti Khadka ${ }^{5,6}$, Khathutshelo Percy Mashige ${ }^{2}$, Joseph Matiya \\ Msosa $^{7}$, Kovin Shunmugam Naidoo ${ }^{2}$
}

1.Department of Optometry, Malawi College of Health Sciences, Lilongwe, Malawi

2. Department of Optometry, College of Health Sciences, University of KwaZulu-Natal, Durban, South Africa

3. School of Optometry and Vision Science, Faculty of Health, Queensland University of Technology, Brisbane, Australia

4. Discipline of Ophthalmology, Save Sight Institute, Sydney Medical School, The University of Sydney, Sydney, Australia

5. South Australian Health and Medical Research Institute, Healthy Ageing Research Consortium, Adelaide, Australia

6. University of South Australia, Business School, Adelaide, Australia

7. Kamuzu Central Hospital, First Eye Hospital, Lilongwe, Malawi

Correspondance: Danesh Kaphle; danesh dinesh.kaphle@gmail.com

\section{Background}

\section{Abstract}

To assess the psychometric properties of the QIRC questionnaire and use it as an outcome measure in spectacle wearers attending an eye clinic in Malawi.

Methods

Participants who had uncorrected distance visual acuity of below 6/18 and improved to 6/9 or better with spectacles on both eyes were included in the study. The participants self-administered the Chichewa version of the QIRC questionnaire that was translated and culturally adapted for Malawian settings. Psychometric evaluation of the QIRC responses was carried out using the WinSteps software (Version 3.92.1; Winsteps, Chicago, IL) by applying the Andrich rating scale model of the Rasch analysis.

Results

One hundred and forty-three participants (mean age \pm standard deviation, $27.64 \pm 2.91$; age range; 16 to 39 years; male, 51.7\%) completed the QIRC. The Chichewa QIRC had satisfactory psychometric properties (Ordered response categories, Person separation index, 1.93; Item separation index, 3.42; Targeting 0.70) including excellent Rasch-model fit statistics (Infit and Outfit MnSq $<1.30$ for all items). The QIRC score was not significantly associated with sex, age, magnitude of refractive error, occupation and status of previous spectacle wear ( $\mathrm{p}>0.05$ for all). The QIRC scores negatively correlated with uncorrected visual acuity (in logMAR) in the better eye (spearman's rho $=-0.34, \mathrm{p}<0.001)$.

Conclusions

The translated and culturally adapted version of the QIRC Questionnaire had satisfactory psychometric properties to measure the refractive error-specific quality of life in Malawi. It performed well as an outcome measure of spectacle wear.

Key words: validation, quality of life, Rasch analysis, spectacles, Malawi

\section{Introduction}

In 2015, there were approximately 36 million blind (presenting visual acuity worse than 3/60) and 217 million moderate and severe visually impaired (presenting visual acuity worse than $6 / 60$ but equal to or better than $3 / 60$ ) people in the world ${ }^{1}$. However, there is a disproportionate distribution of visual impairment across the world with $90 \%$ of visually impaired people living in low-and middle-income countries $^{2}$. It is worth noting that almost two-thirds $(65 \%)$ of blindness, and over three-quarters $(76 \%)$ of moderate and severe visual impairment, are preventable or treatable ${ }^{3}$. Uncorrected refractive error $(53 \%)$ is the leading cause of moderate and severe visual impairment, followed by cataracts $(18 \%)$ and macular degeneration (2\%). Moreover, it is estimated that more than a billion people worldwide suffer from poor vision due to a lack of corrective treatment, such as spectacles, contact lenses or refractive surgery; 100 million of these people are visually impaired ${ }^{4}$. Therefore, refractive error is recognised as a major public health problem that has been prioritised by the VISION 2020: The right to sight campaign ${ }^{2}$.
Studies suggest that uncorrected refractive error is associated with reduced quality-of-life (QoL) and loss of economic productivity, educational and employment opportunities ${ }^{5-7}$. This is despite the fact that the correction of refractive error is a simple and cost-effective intervention that can improve a person's QoL ${ }^{5}$. A number of studies have assessed the impact of refractive error on the vision-related QoL in developed countries $^{8-11}$. These studies highlight the fact that refractive correction may not address all of the QoL issues related to uncorrected refractive error; rather, this may create new issues. For example, people wearing spectacles or contact lenses may find it difficult or inconvenient to look after these products. Similarly, people wearing contact lenses or considering laser refractive surgery may have concerns about the potential complications that may be involved. However, there is a paucity of such studies in low- and middle-income countries, particularly in the African continent. While studies are being conducted to identify the most affordable way of providing refractive services ${ }^{2}$, there is limited evidence related to the impact of refractive correction on QoL, particularly in countries with poor resources. 
The impact of refractive error on the QoL can be assessed quantitatively by using refractive error-related questionnaires $^{12}$, such as the Refractive Status Visual Profile $\left(\right.$ RSVP) ${ }^{13}$, the National Eye Institute Refractive error Quality of Life (NEI-RQL) ${ }^{14}$ and the Quality of life Impact on Refractive Correction (QIRC) ${ }^{15}$. The RSVP and NEI-RQL instruments were developed using traditional methods that employ summary scoring and were found to have poor psychometric properties ${ }^{16,17}$. On the other hand, the QIRC was developed using a modern psychometric method (Rasch analysis $)^{15}$.

Rasch analysis offers several advantages over traditional summary scoring methods. The summary scoring method is based on the addition of ordinal values representing response categories; this method assumes that all items (questions in a questionnaire) are of equal weight and that the response options are equidistant from each other. Summary scoring often assumes that categorical ordinal data are interval level-data. These assumptions are logically erroneous, and were proven false by Rasch analysis ${ }^{18}$. The QIRC, which is a Rasch-based questionnaire, is one of the best patient-reported outcome instruments for refractive error $^{19-21}$. However, the QIRC has not yet been validated after translation to Chichewa in Malawi.

To the best of our knowledge, the impact of refractive error, when corrected by spectacles, has not been assessed in Malawi with regards to quality of life. Therefore, the objectives of this study were to assess the psychometric properties of the QIRC questionnaire and then to evaluate QIRC scores in young adults wearing spectacles in Malawi across demographic and clinical sub-groups of refractive error.

\section{Methods}

\section{Study setting and population}

Malawi, a small landlocked country in Sub-Saharan Africa, is considered as a low-income country by the World Bank ${ }^{22}$. This study was conducted in the eye clinic at Malawi College of Health Sciences, Lilongwe. This clinic provides refractive and other ocular health services to people residing in the central region of Malawi. One hundred and forty-three participants were consecutively recruited from the eye clinic between November 2014 and October 2016. To be eligible for our study, participants had to be aged between 16 and 39 years and had refractive errors (uncorrected visual acuity worse than $6 / 18$ that improved to $6 / 9$ or better after refractive correction in both eyes). This visual acuity cutoff is used by the Malawi College of Health Sciences clinic to provide subsidised spectacles to their patients. Another inclusion criterion was that the participants must be able to read and write fluent Chichewa, the local Malawian language. Participants who had a reduced visual acuity that was secondary to ocular and other ocular and systemic conditions besides refractive error, such as diabetic retinopathy and pregnancy, were excluded from the study. For example, it has been reported that the health-related QoL varies widely with gestation period in pregnant women ${ }^{23}$. In addition, patients with ocular pathologies were referred to the Lions Sight First Eye Hospital located within Kamuzu Central Hospital, Lilongwe for further management.

\section{Ocular examination}

Standard eye examinations were conducted to identify people with refractive errors. Visual acuity was measured with a Snellen chart at $6 \mathrm{~m}$ and converted to $\log \mathrm{MAR}$ acuity for data analysis. External eye examinations, such as cover test, motility tests, and pupil evaluation, were also performed to identify neural problems or misalignment of the eyes. The anterior segment of the eyes was examined grossly with a torch light, and in detail using a slit lamp biomicroscope, where indicated, to rule out ocular infections. Non-cycloplegic objective and subjective refraction were performed to determine the distance prescription for spectacles. The subjective refraction consisted of monocular spherical refraction, Jackson cross cylinder, and Humphriss immediate contrast binocular balancing. The fundus was evaluated with a direct ophthalmoscope to rule out any pathology in the posterior segment. Where indicated, slit lamp biomicroscopy, with a +90 dioptres (D) lens, was used to examine the posterior segment of the dilated eye with the use of $1 \%$ tropicamide eye drops.

Refractive errors were defined as myopia of spherical equivalent refraction $(\mathrm{SER}) \leq-0.75 \mathrm{D}$ sphere, and hyperopia of $\geq+1.00 \mathrm{D}$, and astigmatism of at least $1.00 \mathrm{D}$ difference in refractive error between the two principal meridians. Myopia was sub-divided into low myopia (SER $>-3.00 \mathrm{D})$, moderate myopia (SER between $-3.00 \mathrm{D}$ and $-6.00 \mathrm{D})$, and high myopia (SER $\leq-6.00 \mathrm{D})$. Low hyperopia included SER between +1.00 D and +3.00 D, while high hyperopia was defined as SER $\geq+3.00 \mathrm{D}^{24}$. The SER was calculated as the sum of the spherical power and a half of the cylindrical power for refractive errors.

\section{The QIRC}

The QIRC contains 20 items with five-point response scales ranging from 'not at all' to 'extremely', along with a 'Don't know/Not applicable' option. Despite having relatively fewer items (compared to other common refractive error-specific questionnaires such as the NEI-RQL ${ }^{14}$ and the RSVP ${ }^{13}$ ), the QIRC has a wide coverage of QoL domains. The content of these items is presented in Supplementary Table S1. Studies have demonstrated that the QIRC has good psychometric properties when measured with both traditional and modern psychometric methods $9,15,25$. Furthermore, the QIRC has been proven sensitive to investigate how different types of refractive correction can exert impact on the QoL ${ }^{8}$.

\section{Translation and cultural adaptation of the QIRC questionnaire}

The QIRC questionnaire was translated into Chichewa language following a standard protocol involving forward and backward translation ${ }^{26}$. First, the original QIRC questionnaire was translated into Chichewa by two independent linguists. Then, the Chichewa version of the questionnaire was back translated into English by another two individuals who were fluent in both Chichewa and English languages. Next, the original and the back-translated versions of the QIRC were compared to check for consistency. During translation of the questionnaire, a few of the questions were modified to adapt to local conditions. For instance, 'difficulty with driving' (item 1) was replaced by 'difficulty in cycling or driving'. Similarly, the question related to 'beach' (item no 6) was replaced with 'river' or 'lake' as Malawi does not have access to the sea. In item 7, 'gym/doing keep-fit classes/circuit training' was replaced with 'playing any type of game/exercise'. As we only included people who only wore spectacles to correct their vision, contact lenses and refractive surgery options were omitted from the questionnaire. 
Participants who met the inclusion criteria were provided with an information document in Chichewa language. Two research assistants who were fluent in both Chichewa and English languages administered the Chichewa version of QIRC instrument.

\section{Data management and analyses}

Rasch analysis was carried out to assess the psychometric properties of the QIRC; this was carried out with WinSteps software (Version 3.9 2.1; Winsteps, Chicago, IL)) by applying the Andrich group-rating scale model. The QIRC items were classified into 5 groups: visual function (item 1), symptoms (item 2), convenience (items 3-7), health concerns (items 8-13) and well-being (items 14-20) domains. The rating-scale for the well-being domain was disordered. Ordering of the rating scale for well-being items was fixed by collapsing the response categories 'Fairly often' and 'Very often'. Following Rasch analysis, further analysis was carried out using Stata 11 (Stata Corp. College Station, TX).

Rasch analysis is a probabilistic mathematical model based on the principle that a person with higher ability has a greater chance of being successful in answering an item, and an item with less difficulty is more likely to be answered successfully than the item with more difficulty ${ }^{27}$. This model guides the development and selection of items, and can be applied at two stages: when constructing the measures and when evaluating the constructs, ideally for both ${ }^{28}$.

The model transforms simple ordinal categorical data into interval level data by logarithmic transformation. Item and person estimates are placed in a single linear scale with units as logits (log odd units). Rasch analysis estimates interval level person-measures; higher scores indicate a better QoL status.

Rasch analysis provides insights into a series of important psychometric properties of a patient reported outcome instrument, known as Rasch parameters. These parameters include targeting, unidimensionality, response category functioning, measurement precision and differential item functioning. Rasch parameters act as diagnostic indicators and can be used to select (include or exclude) items in constructing measures ${ }^{29}$. Rasch analysis is an iterative process where item or person estimate cycles are repeated until essential criteria for all Rasch parameters are met. The measurement scale should measure only one underlying construct (unidimensionality). Similarly, the trait values of the response options should increase monotonically in a scale with a uniform spacing between one to the next option (response category functioning). Person separation index or person reliability coefficients are the measures of measurement precision which estimate how many groups with different person ability can be defined by the instrument. Another component of Rasch analysis is the differential item function, which assesses if groups of people with similar latent traits respond differently.

Similarly, item fit statistics indicate how well the items fit together to measure the underlying latent trait. Fit statistics are calculated from the standardized residuals. Infit statistics are information-weighted fit statistics (weighted by variance; the variance is larger for well-targeted responses and smaller for extreme responses $)^{30}$. Therefore, when calculating infit statistics, more weight is given to on-target observations ${ }^{30}$. However, when calculating outfit statistics, equal weighting is given to on-target and off-target observations. Therefore, outfit statistics are influenced by off-target observations ${ }^{30}$.

Those who chose to participate in the study were asked for their verbal consent prior to recruitment. Ethical approval was obtained from the University of KwaZulu-Natal Biomedical Research Ethics Committee and National Health Sciences Research Committees, Malawi. The Head of the Optometry Department at Malawi College of Health Sciences also provided permission to use the eye clinic facilities for the study. The study was conducted in accordance with the tenets of the Declaration of Helsinki.

\section{Results}

Three hundred and twenty-seven subjects, aged between 16 and 39 years, visited the eye clinic during the study period. Of these, 159 subjects did not meet our inclusion criteria either because their visual acuity was beyond the cut-off criteria or because of the presence of an ocular condition other than a refractive error. Furthermore, 25 subjects did not participate in the study despite being eligible to participate. Thus, 143 subjects participated in the final analysis; the participation rate was therefore $85.12 \%$. The mean ( \pm standard deviation) age of the subjects was $27.64 \pm 2.91$ (range: $16-39$ ) years. The general characteristics of the subjects are shown in Table 1. Forty-six participants $(32.3 \%)$ wore spectacles for the first time; in other words, these subjects previously had uncorrected refractive error or they had been wearing spectacles for less than 2 months at the time of recruitment. The mean time of spectacle wearing per day reported was $11.66 \pm 2.63 \mathrm{~h}$ (range: 3 to $17 \mathrm{~h}$ ).

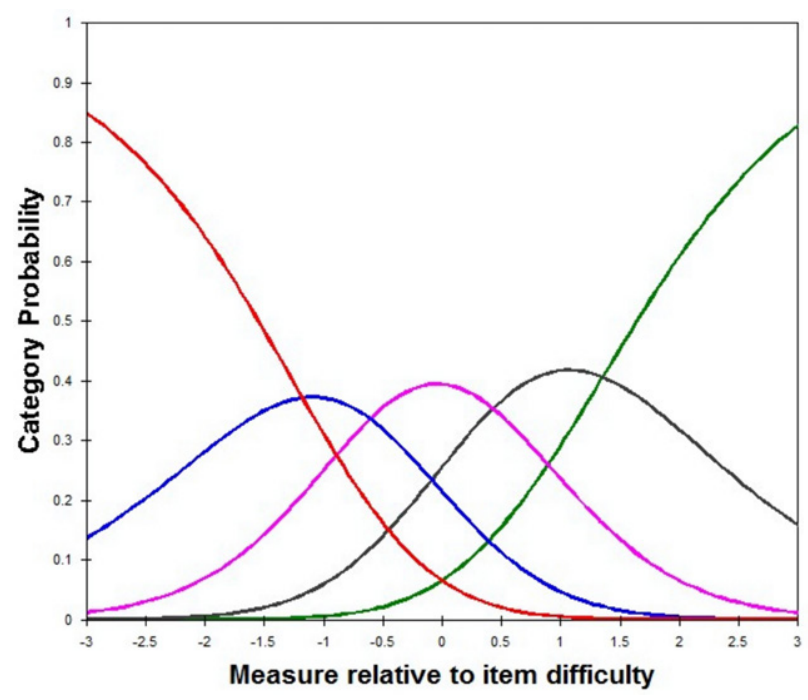

Figure 1. Category probability curves for item 2 'How often have you experienced your eyes feeling tired or strained ?'

Red $=1$, always; blue $=2$, very often; pink $=3$, fairly often; black $=$ 4 , occasionally; green $=5$, never.

\section{Rasch analysis}

Principal component analysis of the residuals showed that the eigen-value of the first contrast was slightly higher, thus indicating that at least three items might form a secondary dimension. Six well-being items had residual loadings $>0.40$. A separate Rasch analysis was performed to investigate the viability of the well-being scale as an independent measure.

The well-being scale had a sub-optimal person-separation index and poor targeting. Removing the well-being items did not improve the psychometric properties of the original QIRC. In the original QIRC, disattenuated correlation (i.e. correlation between the first and second item-clusters 
Table 1. Characteristics of the participants

\begin{tabular}{ll}
\hline Characteristics & Frequency (\%) \\
\hline Sex & $74(51.7)$ \\
Female & $69(49.3)$ \\
Age (years) & \\
Mean $\pm S D$ & $27.64 \pm 6.51$ \\
Range & $16-39$ \\
Magnitude of refractive error (D) & $-2.46 \pm 2.91$ \\
Mean $\pm S D$ & -15.0 to 3.25 \\
Range &
\end{tabular}

\section{Type of refractive error}

Low myopia $(\leq-0.75$ to $>-3.00 \mathrm{D})$

$52(36.4)$

Moderate myopia ( $\leq-3.00$ to $>-6.00 \mathrm{D})$

$29(21.0)$

High myopia $(\leq-6.00 \mathrm{D})$

Low hyperopia $(\geq+1.00$ to $<+3.00 \mathrm{D})$

High hyperopia ( $\geq+3.00 \mathrm{D}$ )

Astigmatism ( $\geq 1.0 \mathrm{D})$

$0.60(0.52-1.0)$

$0.48-2.0$

\section{Uncorrected VA in better eye (logMAR)}

Median (IQR)

Range

\section{Prior spectacles wear \\ $<2$ months $^{a}$ \\ Occupation}

Students

Businessman/woman

Housewives

Employed

Public Service employee

Health professionals

Teachers

Farmers

Others

QIRC score ( $\mathrm{N}=135)$

Mean \pm SD
$63.13 \pm 12.88$ units

Range $27.07-97.06$ units

IQR, interquartile range; QIRC, Quality-of-life Impact of Refractive Correction; SD, standard deviation; VA, visual acuity.

aPrior spectacles wear $<2$ months category includes participants with previously uncorrected refractive error.

after eliminating the weakening effect of noise in the measurement) between the first and the second item clusters on the Rasch principal component analysis of the residuals was 1.0, thus indicating that the clusters of items were essentially measuring the same construct (quality of life). Therefore, we decided not to split the QIRC questionnaire.

Table 2. Rasch parameters for the QIRC iterations

\begin{tabular}{|c|c|c|c|c|}
\hline Parameters & $\begin{array}{l}\text { QIRC-original } \\
\text { scale }\end{array}$ & $\begin{array}{l}\text { First contrast } \\
\text { (Well-being: } \\
\text { items 14-20) } \\
\text { after collapsing } \\
\text { the disordered } \\
\text { categories }\end{array}$ & $\begin{array}{l}\text { First dimension } \\
\text { (Items 1-13) }\end{array}$ & Final iteration ${ }^{a}$ \\
\hline No. of items & 20 & 7 & 13 & 20 \\
\hline $\begin{array}{l}\text { Response } \\
\text { category ordering } \\
\text { (thresholds) }\end{array}$ & $\begin{array}{l}\text { Well-being scale } \\
\text { disordered }\end{array}$ & Ordered & Ordered & Ordered \\
\hline $\begin{array}{l}\text { Person } \\
\text { separation index }\end{array}$ & $1.86(0.78)$ & $1.55(0.71)$ & $1.82(0.77)$ & $1.93(0.79)$ \\
\hline $\begin{array}{l}\text { (person reliability) } \\
\text { Item separation } \\
\text { index (item } \\
\text { reliability) }\end{array}$ & $3.45(0.92)$ & $3.97(0.94)$ & $3.37(0.92)$ & $3.42(0.92)$ \\
\hline $\begin{array}{l}\text { Targeting, } \\
\text { difference } \\
\text { between person } \\
\text { \& item means } \\
\text { (logits) }\end{array}$ & & & & - \\
\hline Item infit MnSq & 2 (items 8,13 ) & 1 (item 20) & 2 (items 8, 13) & \\
\hline $\begin{array}{l}>1.3 \\
\text { Item outfit MnSq } \\
>1.3 \\
\text { PCÄ: variance } \\
\text { explained by } \\
\text { the measure/ } \\
\text { disattenuated } \\
\text { correlation } \\
\text { between } 1 \text { st and } \\
2 \text { nd item-clusters } \\
\left(r_{d}\right) / \text { eigen value of } \\
\text { the first contrast/ } \\
\text { items with } \\
\text { residuals loading } \\
>0.40 \text { to first } \\
\text { contrast }\end{array}$ & $\begin{array}{l}3 \text { (items } 20 \text {, } \\
8,13) \\
31.2 \% / \\
r_{d}=1.0 / 3.37 / 6 \\
\text { (items 14-19) }\end{array}$ & $\begin{array}{l}- \\
52.4 \% / \\
r_{d}=1.0 / 1.96 / 2 \\
\text { items }(14,15)\end{array}$ & $\begin{array}{l}2 \text { (items } 8,13 \text { ) } \\
37.9 \% / \\
r_{d}=1.0 / 2.45 / 4 \\
\text { items }(10-13)\end{array}$ & $\begin{array}{l}- \\
30.8 \% / \\
r_{d}=0.96 / 3.10 / 6 \\
\text { (items 14-19) }\end{array}$ \\
\hline
\end{tabular}

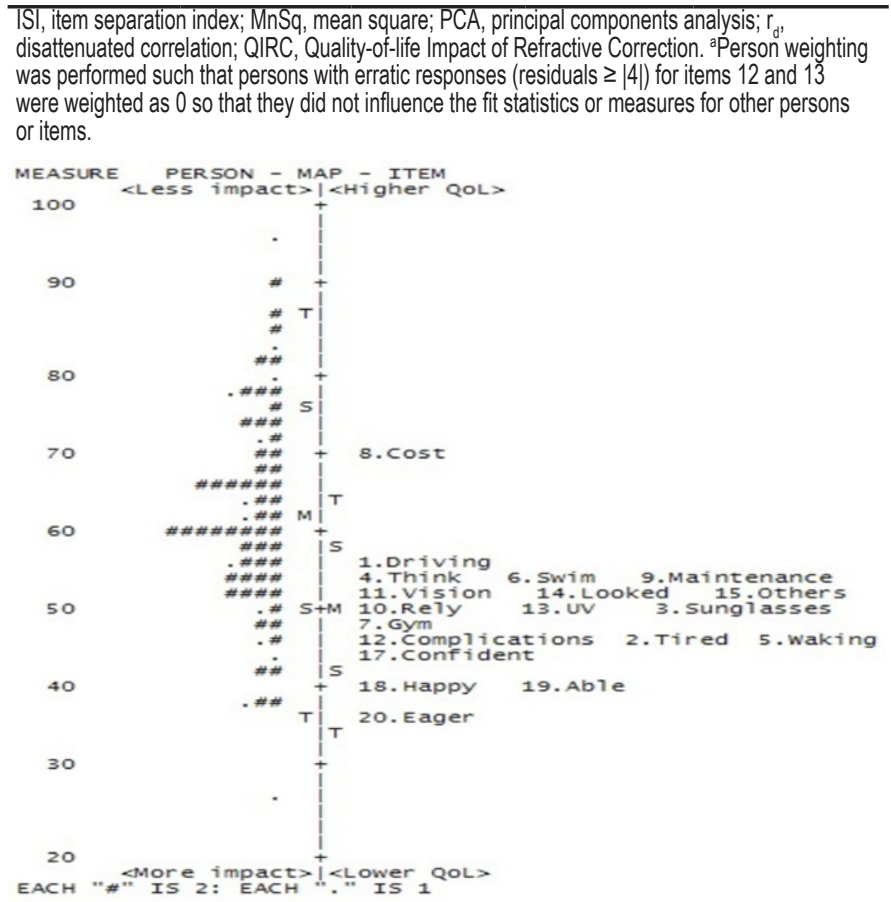

Figure 2. Person-item-map. Persons are located in the left, with their abilities in the latent traits given from low (at the bottom) to high (at the top). On the right side, items have been replaced by the difficulty level of the latent trait (i.e. the quality of life) from low (bottom) to high (top). M, mean; S, one standard deviation from the mean; $T$, two standard deviations from the mean. 
Table 3. QIRC score in relation to sex, age, magnitude of refractive error, occupation and previous spectacle wearing

\begin{tabular}{lll}
\hline Variables & Mean \pm SD & $\begin{array}{l}F \text { (Independent } \\
\text { t-test) }\end{array}$ \\
& & $p$ \\
\hline Sex & 2.11 & 0.14
\end{tabular}

$\begin{array}{ll}\text { Male }(\mathrm{N}=69) & 61.56 \pm 11.78 \\ \text { Female }(\mathrm{N}=66) & 64.77 \pm 13.84\end{array}$

Age group (years)
$16-27(\mathrm{~N}=73)$

$28-39(\mathrm{~N}=62) \quad 65.52 \pm 12.61$

Magnitude of

refractive error

Below SER $\pm 3.00 \mathrm{D} \quad 66.02 \pm 12.02$

$(\mathrm{N}=52)$

Equal to more than

$\mathrm{SER} \pm 3.00 \mathrm{D}(\mathrm{N}=38)$

\begin{tabular}{|c|c|}
\hline $\begin{array}{l}\text { Astigmatism }(\mathrm{N}=45) \\
(\geq 1.00 \mathrm{D}) \\
\text { Occupation }\end{array}$ & $62.48 \pm 12.26$ \\
\hline Students (N=65) & $62.53 \pm 11.63$ \\
\hline Non-students $(\mathrm{N}=70)$ & $63.68 \pm 1$ \\
\hline
\end{tabular}

Prior spectacles

wear

$\geq 2$ months $(\mathrm{N}=65)$

$59.58 \pm 11.40$

$<2$ months $(\mathrm{N}=32)$

$58.66 \pm 11.02$
The final Rasch iteration demonstrated that all items had good fit statistics and the QIRC had satisfactory measurement precision (Supplementary Table S2). Item misfits were fixed by person-weighting the erratic responses to items 13 and 12. The response categories were ordered and the thresholds were advanced monotonically (Figure 1). Targeting between person ability and item difficulty was satisfactory (Table 2). There was no significant differential item functioning observed by sex, age groups, the severity of refractive error and previous history of wearing glasses. The final Rasch scale was converted into a 0 to 100 scale with the item mean located at 50 units (Figure 2). Item 8 (cost to buy spectacles) had the highest item measure, thus indicating that cost was the most impactful issue with regards to QoL. Item 20 (eager to try new things) had the lowest item measure (Supplementary Table S2). Person measures were used for post hoc tests to evaluate the impact of wearing spectacles on the QoL of participants.

\section{Relationship between QIRC scores and other variables}

There were no significant differences in QIRC score with respect to different sexes $(p=0.14)$, the magnitude of refractive error (i.e. below SER $\pm 3.00 \mathrm{D}$ versus $\mathrm{SER} \pm 3.00 \mathrm{D}$ or above) or astigmatism $(p=0.07)$, occupation (i.e. students versus non-students; $p=0.60$ ) and previous spectacle wearing $(p=0.70)$ (Table 3). Older participants had significantly higher mean QIRC scores $(65.52 \pm 12.61)$ than younger participants (61.10 $\pm 12.84, p=0.04)$. The QIRC score was negatively correlated with uncorrected visual acuity $(\log M A R)$ in the better eye (Spearman's rho $=-0.30 ; p=0.001$ ).

\section{Discussion}

This study used the QIRC to investigate the QoL of Malawians aged between 16 and 39 years who wore spectacles to correct their refractive errors. Using Rasch analysis, the original

tion; SD, standard deviation. ${ }^{\text {aF }}$ for ANOVA test.

Table 4. Summary of studies conducted using the QIRC questionnaire

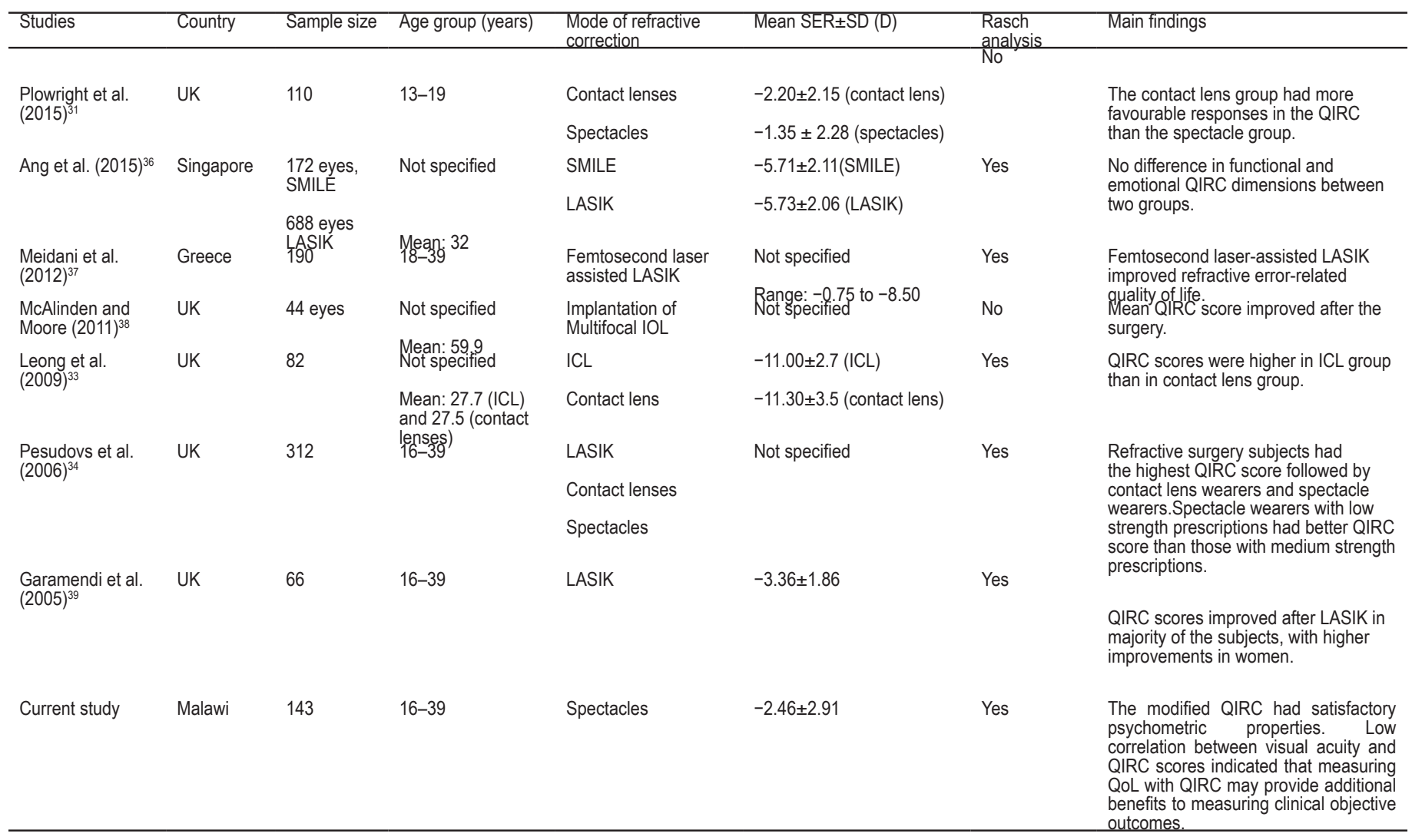


Chichewa QIRC demonstrated satisfactory psychometric properties, including excellent fit statistics.

To the best of our knowledge, Malawi is the first country in which the Chichewa version of the QIRC questionnaire has been used to measure QoL with respect to refractive error using Rasch analysis. The QIRC questionnaire has a wide coverage of QoL domains, including activity limitations, symptoms, convenience, economic issues, health concerns and well-being ${ }^{15}$. A recent systematic review reported that the QIRC questionnaire has better psychometric properties, including measurement precision, than more widely used traditional refractive error-specific patient-reported outcome questionnaires, such as the NEI-RQL and RSVP ${ }^{19}$. The content of the QIRC questionnaire was developed following comprehensive consultation with subjects experiencing refractive correction ${ }^{19}$.

In this study, the QIRC scale exhibited some indications of multidimensionality and was therefore similar to a previous study by Ang et al., ${ }^{25}$ who split the QIRC into 'functional' and 'well-being' scales ${ }^{25}$. In our study, the well-being items (item numbers 14 to 20) did not form an independent valid scale, unlike the study by Ang et al. ${ }^{25}$ The major issues with this scale were that the measurement precision fell below an acceptable level. Poor precision with regards to the well-being items may relate to a high ceiling effect as nearly two-thirds of the responses for these items were for the category 'never'. Floor and ceiling effects exacerbate noise in the measurement and reduce precision ${ }^{18}$. Despite some evidence of multidimensionality, the well-being items were not split from the main QIRC scale. Quality-of- life is a multidimensional concept and therefore absolute unidimensionality may not be achieved in practice. As the QIRC has a larger number of well-being items than other quality-of-life domains, these items tended to group together to form a subscale.

Although the QIRC was originally developed in a highresource setting, the findings of our study demonstrate that it may be used to evaluate QoL in refractive error in low-income countries. This is an important finding as comprehensive and high-quality patient-reported outcome instruments for refractive error are not particularly well developed for low resource settings ${ }^{19}$. Our findings highlight the clear potential for the QIRC to compare refractive errorspecific QoL in different sub-groups (e.g. spectacles versus contact lenses) in low-income countries.

The QIRC questionnaire was developed and validated for use in participants who were corrected for refractive error with spectacles, contact lenses or refractive surgery ${ }^{15}$. So far, all the studies that have used the QIRC questionnaire included a combination of participants with two or more types of refractive correction (i.e. spectacles, contact lenses or refractive surgery) (Table 4) ) $^{8-10,25,31-33}$. However, in this study setting, refractive error is typically corrected with spectacles. Contact lenses are not a common mode of refractive correction in Malawi, and refractive surgery is not available. In addition, all the previous studies which used the QIRC questionnaire were conducted in high-income countries, the majority of these taking place in the UK (5 out of 7). This makes the comparison of our findings with other studies difficult.

In this study, female participants had slightly higher QIRC scores than male participants; however, the difference between sexes was not statistically significant. In a previous study, Pesudovs et $a .^{8}$ found no difference in the QIRC scores related to refractive error when compared between men and women. In contrast, Garamendi et al. ${ }^{10}$ found that the preoperative QIRC score was significantly worse for women; however, after refractive surgery, the overall score improved more in women. In the current study, the QIRC score was significantly associated with age: older participants (28 years and above, 65.52 12.61 ) had higher QIRC scores than younger participants (61.10 \pm 12.84$)$, possibly because of the longer duration of performing usual activities with spectacles. In the study by Pesudovs et $a .^{8}$ the refractive surgery group were significantly older than the spectacle and contact lens wearers; however, subgroup analysis by age was not performed.

Our study found that the mean QIRC scores for the participants with high SER and astigmatism were lower than for those with low SER and astigmatism, respectively. However, these differences were not statistically significant. Similarly, there was no difference in the mean QIRC score when compared between new and existing spectacles wearers although wearers were anticipated to have lower QoL scores than existing spectacle wearers. We believe that this discrepancy arose because of the low power of the test because of the relatively small sample size. We recommend that a larger sample size should be used in future studies of this nature.

We found that the QIRC scores were weakly correlated with uncorrected visual acuity. This challenges the clinical perspectives that consider visual acuity as the major outcome measure of refractive correction. This finding highlights the additional benefit of incorporating patient-reported outcome instruments in the clinical care of people with refractive error. Patient-reported outcomes should therefore be an important part of comprehensive outcome assessment in refractive correction.

This study had some limitations that need to be considered. The subjects aged between 16 and 39 years, who had an uncorrected visual acuity worse than $6 / 18$ that improved to $6 / 9$ or better after refractive correction, were recruited from the Malawi College of Health Sciences eye clinic. Consequently, the findings may not be generalisable for the entire Malawian population with refractive error. A population-based study would provide more representative findings at the national level. It is possible that some ocular conditions that may not cause reduced visual acuity, but create discomfort such as ocular allergy, may have been missed because of our strict exclusion criteria and therefore could have affected the QoL scores. We believe that the tasks that impact on the QoL of the participants in our study might be quite different to those that impact on UK-based participants. It is possible that a different low- and middle-income country based QoL measure, if developed and validated, could provide better validity results for African settings. In a recent systematic review, Kandel et.al. ${ }^{19}$ were also sceptical about the application of the QIRC questionnaire in different low- and middle-income country settings. We also acknowledge that a modified version of the QIRC instrument, if designed for spectacle wearers alone, would provide better results. Pesudovs et al. ${ }^{15}$ suggested that different questionnaires may be ideal if developed for each mode of refractive correction separately, even though the instrument was found to be suitable for refractive correction with spectacles, contact lenses or refractive surgery. This 
suggestion was supported when the Contact Lens Impact on Quality of life (CLIQ) questionnaire was developed and found to have better validity for contact lens wearers ${ }^{34}$.

Another limitation associated with the QIRC instrument is that the original questionnaire was developed from a prepresbyopic population, and has not been validated in a presbyopia population. Consequently, the QIRC may not be sensitive enough to evaluate vision-related quality of life in a presbyopic population. Therefore, we excluded participants with presbyopia from the current study. Considering that $25 \%$ (1.8 billion) of people across the world who are aged 35 years or over have presbyopia, and that almost $46 \%$ of this particular population have near visual impairment due to either no or inadequate vision correction ${ }^{35}$, there is a clear justification for future research to target the development of a modified QIRC instrument for the presbyopic population.

This is the first study to use the QIRC questionnaire in the African continent to investigate the quality of life among people with refractive error corrected with spectacles. Although the QIRC was originally developed in a highresource setting, our findings show that it could also be used in Malawi, a low-resource setting. However, as with any patient-reported outcome measure, the QIRC should be culturally adapted and tested for validity and psychometric properties before applying it as a routine outcome measure. Recent studies have discussed the exciting opportunity of implementing a new generation patient-reported outcome instrument for refractive error, in the form of item-banking and computer adaptive testing ${ }^{19,35}$. Item-banking may address the limitations of existing paper-based questionnaires in providing comprehensive and scientific measurement of QoL parameters in both high- and low-resource settings ${ }^{19,35}$.

\section{Acknowledgements}

The authors would like to thank Emmanuel Kanyika, Dausi Bonongwe, Dr Carl Holladay Abraham and Mr Denis Simango of Malawi College of Health Sciences for their contributions during the data collection period. Our thanks also go to Mr Nyika Mtemeri for assistance with data analysis. In particular, we extend our special thanks to the participants who volunteered to take part in this study.

\section{References}

1. Bourne RRA, Flaxman SRF, Braithwaite T, Cicinelli MV, Das A, Jonas JB, et al. Magnitude, temporal trends, and projections of the global prevalence of blindness and distance and near vision impairment: a systematic review and meta-analysis. Lancet Glob Health. 2017;5(9):e888-97.

2. World Health Organization. 2007. Global initiative for the elimination of avoidable blindness: Action lan 2006-2011 [Internet]. [cited 2020 Mar 1]. Available from:https://apps.who.int/iris/bitstream/ handle/10665/43754/9789241595889_eng.pdf.

3. Bourne RR, Stevens GA, White RA, Smith JL, Flaxman SR, Price $\mathrm{H}$, et al. Causes of vision loss worldwide, 1990-2010: a systematic analysis. Lancet. 2013;1(6):e339-49.

4. Durr NJ, Dave SR, Lage E, Marcos S, Thorn F, Lim D. From unseen to seen: tackling the global burden of uncorrected refractive errors. Annu Rev Biomed Eng. 2014;16:131-53.

5. Smith, TST, Frick, KD, Holden BA, Fricke TR, Naidoo, KS. Potential lost productivity resulting from the global burden of uncorrected refractive error. Bull World Health Organ. 2009;87: 431-7.

6. Naidoo KS, Jaggernath J. Uncorrected refractive errors. Indian J Ophthalmol. 2012;60(5):432-7.
7. Kandel H, Khadka J, Shrestha MK, Sharma S, Neupane Kandel $\mathrm{S}$, Dhungana $\mathrm{P}$, et al. Uncorrected and corrected refractive error experiences of Nepalese adults: a qualitative study. Ophthalmic Epidemiol. 2017;25(2):1-15.

8. Pesudovs K, Garamendi E, Elliott D. A quality of life comparison of people wearing spectacles or contact lenses or having undergone refractive surgery. J Refract Surg. 2006;22(1):19-27.

9. Meidani A, Tzavara C, Dimitrakaki C, Pesudovs K, Tountas Y. Femtosecond laser-assisted LASIK improves quality of life. J Refract Surg. 2012;28(5):319-26.

10. Garamendi E, Pesudovs K, Elliott DB. Changes in quality of life after laser in situ keratomileusis for myopia. J Cataract Refract Surg. 2005;31(8):1537-43.

11. Kandel H, Khadka J, Goggin M, Pesudovs K. Impact of refractive error on quality of life: a qualitative study. Clin Exp Ophthalmol. 2017;45:677-88.

12. Pesudovs K. Item banking: a generational change in patient-reported outcome measurement. Optom Vis Sci. 2010;87(4):285-93.

13. Vitale S, Schein OD, Meinert CL, Steinberg EP. The refractive status and vision profile: A questionnaire to measure vision-related quality of life in persons with refractive error. Ophthalmology. 2000;107(8):152939.

14. Hays RD, Mangione CM, Ellwein L, Lindblad AS, Spritzer KL, McDonnell PJ, et al. Psychometric properties of the National Eye Institute-refractive error quality of life instrument. Ophthalmology. 2003;110(12):2292-301.

15. Pesudovs K, Garamendi E, Elliott DB. The Quality of Life Impact of Refractive Correction (QIRC) questionnaire: Development and validation. Optom Vis Sci. 2004;81(10):769-77

16. Lévy P, Elies D, Dithmer O, Gil-Campos I, Benmedjahed K, Berdeaux G, et al. Development of a new subjective questionnaire: The Freedom from Glasses Value Scale (FGVS). J Refract Surg. 2010;26(6):438-46.

17. Erickson DB, Stapleton F, Erickson P, Du Toit R, Giannakopoulos E, Holden B. Development and validation of a multidimensional qualityof-life scale for myopia. Optom Vis Sci. 2004;81(2):70-81.

18. Kandel H, Khadka J, Pesudovs K. Intensive blood-pressure treatment and patient-reported outcomes. N Engl J Med. 2017;377(21):2096-7.

19. Kandel H, Khadka J, Goggin M, Pesudovs K. Patient reported outcomes for assessment of quality of life in refractive error: a systematic review. Optom Vis Sci. 2017;94(12):1102-19.

20. Kandel H, Khadka J, Lundström M, Goggin M, Pesudovs K. Questionnaires for measuring refractive surgery outcomes. J Refract Surg. 2017;33(6):416-24.

21. Khadka J, McAlinden C, Pesudovs K. Quality assessment of ophthalmic questionnaires: review and recommendations. Optom Vis Sci. 2013;90(8):720-44.

22. World Bank Open Data 2019 [Internet]. [cited 2019 Apr 10]. Available from: https://data.worldbank.org/country/malawi.

23. Morin M, Claris O, Dussart C, Frelat A, de Place A, Molinier L, et al. Health-related quality of life during pregnancy: A repeated measures study of changes from the first trimester to birth. Acta Obstet Gynecol Scand. 2019;98(10):1282-91.

24. Williams KM, Verhoeven VJ, Cumberland P, Bertelsen G, Wolfram $\mathrm{C}$, Buitendijk GH, et al. Prevalence of refractive error in Europe: the European Eye Epidemiology (E3) Consortium. Eur J Epidemiol. 2015;30(4):305-15.

25. Ang M, Ho H, Fenwick E, Lamoureux E, Htoon HM, Koh J, et al. Vision-related quality of life and visual outcomes after small-incision lenticule extraction and laser in situ keratomileusis. J Cataract Refract Surg. 2015;41(10):2136-44. 
26. Wild D, Grove A, Mona Martin M, Eremenco S, McElroy S. Principles of good practice for the translation and cultural adaptation process for Patient-Reported Outcomes (PRO) Measures: Report of the ISPOR Task Force for translation and cultural adaptation. Value Health. 2005;8(2):94-104.

27. Rasch G. Probabilistic models for some intelligence and attainment tests. Copenhagen: Danmarks Paedagogiske Institut;1960.

28. Bond T, Fox CM. A synthetic review. In: Bond T, Fox CM, editors. Applying the Rasch model: Fundamental measurement in the human sciences. 3rd ed. New York and London: Taylor \& Francis Group; 2015. p. 296-324.

29. Yan Z, Stone G, Betltyukova S. Making measures, setting standards, and Rasch regression. In: Bond T, Fox CM, editors. Applying the Rasch model: Fundamental measurement in the human sciences. 3rd ed. New York and London: Taylor \& Francis Group; 2015. p. 187-225.

30. Bond T, Fox CM. Rasch model requirements: Model fit and unidimensionality. In: Bond T, Fox CM, editors. Applying the Rasch model: Fundamental measurement in the human sciences. 3rd ed. New York and London: Taylor \& Francis Group; 2015. p. 265-95

31. Plowright AJ, Maldonado-Codina C, Howarth GF, Kern J, Morgan PB. Daily disposable contact lenses versus spectacles in teenagers. Optom Vis Sci. 2015;92(1):44-52.

32. McAlinden C, Moore JE. Multifocal intraocular lens with a surfaceembedded near section: Short-term clinical outcomes. J Cataract Refract Surg. 2011;37(3):441-5.
33. Ieong A, Rubin GS, Allan BDS. Quality of life in high myopia: Implantable collamer lens implantation versus contact lens wear. Ophthalmology. 2009;116(2):275-80.

34. Pesudovs K, Garamendi E, Elliott DB. The Contact Lens Impact on Quality of Life (CLIQ) questionnaire: Development and validation. Invest Ophthalmol Vis Sci. 2006;47(7):2789-96.

35. Kandel H, Khadka J, Fenwick E, Sharma S, Sharma B, Kafle K, et al. Constructing item banks for measuring quality of life in refractive error. Optom Vis Sci. 2018;95(7):575-87.

36. Ang M, Ho H, Fenwick E, Lamoureux E, Htoon HM, Koh J, et al. Vision-related quality of life and visual outcomes after small-incision lenticule extraction and laser in situ keratomileusis. J Cataract Refract Surg. 2015;41(10):2136-44.

37. Meidani A, Tzavara C, Dimitrakaki C, Pesudovs K, Tountas Y. Femtosecond laser-assisted LASIK Improves Quality of Life. J Refract Surg. 2012;28(5):319-26.

38. McAlinden C, Moore JE. Multifocal intraocular lens with a surfaceembedded near section: Short-term clinical outcomes. J Cataract Refract Surg. 2011;37(3):441-5.

39. Garamendi E, Pesudovs K, Elliott DB. Changes in quality of life after laser in situ keratomileusis for myopia. J Cataract Refract Surg. 2005;31(8):1537-43. 
Supplementary Table S1. Description of the modified Quality of life Impact with

\section{Refractive Correction (QIRC) instrument}

\begin{tabular}{|c|c|c|}
\hline Domains & Item no. & Contents \\
\hline Visual function & 1 & Difficulty in driving or cycling in glare conditions \\
\hline Symptoms & 2 & During the past month, eyes feeling tired or strained \\
\hline Convenience & $3-7$ & $\begin{array}{l}\text { Trouble not being able to use off-the-shelf (non- } \\
\text { prescription) sunglasses } \\
\text { Trouble before doing things; e.g. travelling, sport, going } \\
\text { swimming } \\
\text { Trouble not being able to see when you woke up; e.g. go } \\
\text { to the bathroom, look after a baby, see alarm clock } \\
\text { Trouble not being able to see when on the lakeshore or } \\
\text { swimming in the river or lake or pool, because you do } \\
\text { these activities without spectacles } \\
\text { Trouble when you wear spectacles when using a gym or } \\
\text { any other exercise }\end{array}$ \\
\hline Health concerns & $8-13$ & $\begin{array}{l}\text { Concerns about the initial and ongoing cost to buy your } \\
\text { current spectacles } \\
\text { Concerns about the cost of unscheduled maintenance of } \\
\text { your spectacles; e.g. breakage, loss, new eye problems } \\
\text { Concerns about having to increasingly rely on your } \\
\text { spectacles since you started to wear them } \\
\text { Concerns about your vision not being as good as it could } \\
\text { be } \\
\text { Concerns about medical complications from your } \\
\text { spectacles } \\
\text { Concerns about eye protection from ultraviolet radiation }\end{array}$ \\
\hline Well-being & $14-20$ & $\begin{array}{l}\text { During the past month, how much of the time you felt that } \\
\text { you looked your best } \\
\text { During the past month, how much of the time have you felt } \\
\text { that you think others see you the way you would like them } \\
\text { to (e.g. intelligent, sophisticated, successful, cool)? } \\
\text { During the past month, how much of the time have you felt } \\
\text { complimented/flattered } \\
\text { During the past month, how much of the time have you felt } \\
\text { confident? } \\
\text { During the past month, how much of the time have you felt } \\
\text { happy } \\
\text { During the past month, how much of the time have you felt } \\
\text { able to do the things you want to do } \\
\text { During the past month, how much of the time have you felt } \\
\text { eager to try new things }\end{array}$ \\
\hline
\end{tabular}


Supplementary Table S2. Item measures and fit statistics of QIRC items 1 to 20

\section{Item Item}

No.

1 How much difficulty do you have driving or cycling in glare conditions?

2 During the past month, how often have you experienced your eyes feeling tired or strained?

3 How much trouble is not being able to use off-the-shelf (non-prescription) sunglasses?

4 How much trouble is having to think about your spectacles before doing things; e.g. travelling, sport, going swimming?

5 How much trouble is not being able to see when you wake up; e.g. to go to the bathroom, look after a baby, see alarm clock?

6 How much trouble is not being able to see when you are in the lake or swimming in the river or pool, because you do these activities without spectacles or contact lenses?

7 How much trouble is your spectacles when you wear them when playing any time of exercise or game?

8 How concerned are you about the initial and ongoing cost to buy your current spectacles?

9 How concerned are you about the cost of unscheduled maintenance of your spectacles; e.g. breakage, loss, new eye problems?

10 How concerned are you about having to increasingly rely on your spectacles since you started to wear them?

11 How concerned are you about your vision not being as good as it could be?

12 How concerned are you about medical complications from your spectacles?

13 How concerned are you about eye protection from ultraviolet (UV) radiation?

14 During the past month, how much of the time have you felt that you have looked your best?

15 During the past month, how much of the time have you felt that you think others see you the way you would like them to (e.g. intelligent, sophisticated, successful, cool, etc.)?

16 During the past month, how much of the time have you felt complimented/flattered?

17 During the past month, how much of the time have you felt confident?

18 During the past month, how much of the time have you felt happy?

19 During the past month, how much of the time have you felt able to do the things you want to do?

20 During the past month, how much of the time have you felt eager to try new things?
Item measure Infit Outfit

$\mathrm{MnSq} \mathrm{MnSq}$

(SE)

\begin{tabular}{|c|c|c|}
\hline $56.19(1.86)$ & 0.91 & 0.92 \\
\hline $45.91(1.7)$ & 0.96 & 0.94 \\
\hline $49.44(1.64)$ & 1.17 & 1.10 \\
\hline 53.53 (1.68) & 1.04 & 1.01 \\
\hline $45.97(1.66)$ & 0.99 & 0.97 \\
\hline 54.39 (1.69) & 1.16 & $1.1 \varepsilon$ \\
\hline $48.4(1.76)$ & 1.08 & 1.13 \\
\hline $69.72(2.11)$ & 1.02 & 1.08 \\
\hline $54.77(2.35)$ & 1.06 & 1.05 \\
\hline $49.77(2.43)$ & 0.82 & $0.7 s$ \\
\hline $51.75(2.38)$ & 0.85 & 0.8 \\
\hline $46.64(2.47)$ & 0.85 & 0.86 \\
\hline $50.25(2.44)$ & 1.07 & 1.1 \\
\hline 52.85 (1.91) & 1.05 & 1.0 \\
\hline $53.17(1.91)$ & 1.06 & 1.06 \\
\hline 52.34 (1.93) & 1.31 & 1.2 \\
\hline $44.1(2.02)$ & 0.74 & 0.7 \\
\hline $40.14(2.10)$ & 0.86 & 0.8 \\
\hline $40.7(2.06)$ & 0.85 & 0.8 \\
\hline $36.85(2.18)$ & 0.96 & 1. \\
\hline
\end{tabular}

MnSq, mean square; SE, standard error. 